\title{
Effect of plyometric exercise in water and grass on indicators of protein
}

\section{catabolism, muscle damage and muscle inflammation}

\section{Ashraf Mohamed Mohamed Ali Wahba}

\section{Mohamed Mustafa Taha Hassan EI Nahass}

\section{ABSTRACT :}

the purpose of the present study was to compare protein catabolism indicator (blood urea nitrogen $[\mathrm{BUN}]$ ), muscle damage indicators ( lactate dehydrogenase (LDH) and myoglobin (Mb) ) and inflammation indicator (interleukin (IL6) ) after a single plyometric exercise (PE) session performed in water and on grass . Fifteen healthy and physically active male third year students at the faculty of physical education for boys, with a mean age of $20.62 \pm .59$ years, a height of $173.8 \pm 4.95 \mathrm{~cm}$, and a body mass of $72.67 \pm 8.27 \mathrm{~kg}$ participated in this study . the result showed that there are statistically significant differences between aquatic and Grass group measurements in all variables of the research except LDH . The present study can recommend that coaches and strength \& conditioning professionals use Aquatic Plyometric or safe surfaces like a firm surface for plyometric training to decrease muscle damage.

\section{INTRODUCTION}

Plyometric training is a form of muscle power training (speed - strength) and has many important benefits, including progression of vertical jump (VJ), strength $[1,26]$, speed [3,26], agility [3], balance [2]. However it can also lead to damage and swelling and pain in the muscles, which may cause a decrease in muscle strength $[19,30]$,muscle power $[3,8]$ and a lack of range of motor joints (Range of motion) $[8,24]$ and may cause injuries in the muscle structure, especially in the lower limb [27].

During plyometric exercise, such as Squat jump, Tuck jump, Power skipping, Alternate leg bounding, Box jumps, etc., the stretch-shortening cycle (SSC) especially during landing plays an important role in improving strength, power, speed, core stability, balance, joint function, and neuromuscular control $[10,20]$. The SSC cycle consists of three phases a rapid eccentric muscle contraction phase,an amortization phase followed by a rapid concentric contraction phase in the same agonist muscles [14]. This rapid combination between eccentric and concentric contraction prepare a physiological benefits in muscular power development during the concentric phase [1]. The amortization phase or "time to rebound" is the most important phase in plyometric activity which depends on stretch reflex and this phase is crucial in developing power production [13].However, some of studies showed that eccentric contractions involved in plyometrics exercise cause muscle damage and inflammation [2,30].Moreover, plyometric exercise (PE) on the solid surfaces frequently cause muscle damage in the knee extensors $[17,30]$.

However, plyometric training in water probably present an optimal load with less muscle damage, many studies have indicated that damage indicators are lower after aquatic plyometric training in comparison with plyometric training on land $[11,20,21,25,26,29]$. Furthermore, Studies of Aquatic plyometric training showed statistically significant improvements in vertical jump, speed, agility and muscular strength [21,23,28,29].

Monitoring of the muscle damage indicators plays an important role in controlling the physiological and training status of athletes, however adaptation of the muscular system to physical load is correlating with an improvement in enzyme activity and stress indicators $[5,6,7]$.

Although several studies have explored how the impact of plyometric training on muscle damage is affected by the nature of the landing and take-off surface, such as sand 
against grass [16], sand against wood [24] and aquatic against land [26], and aquatic against sand and firm [15], No study has directly compared aquatic against grass in relation to muscle damage and inflammation when performing a similar number of plyometric jumps.

Therefore, the purpose of the present study was to compare protein catabolism indicator (blood urea nitrogen [BUN]), muscle damage indicators (lactate dehydrogenase (LDH) and myoglobin(Mb)) and inflammation indicator (interleukin (IL6) ) after a single plyometric exercise (PE) session performed in water (AP) and on grass (GP) .

\section{METHODS}

\section{Subjects}

Fifteen healthy and physically active male third year students at the faculty of physical education for boys, with a mean age of $20.62 \pm .59$ years, a height of $173.8 \pm 4.95$ $\mathrm{cm}$, and a body mass of $72.67 \pm 8.27 \mathrm{~kg}$ (Table 1) participated in this study . No history of injury was reported in the previous six months.

TABLE 1. Subjects characteristics $(N=15)$.

\begin{tabular}{c|c|c|c}
\hline & Mean & Standard deviation & Skewness \\
\hline Age $(\mathrm{y})$ & 20.6200 & 0.59185 & 1.146 \\
\hline Body mass $(\mathrm{kg})$ & 173.8000 & 4.94542 & 0.841 \\
\hline Height $(\mathrm{cm})$ & 72.6667 & 8.26928 & 0.569 \\
\hline
\end{tabular}

\section{Biomedical Measurement}

Indirect markers of protein catabolism [BUN], muscle damage indicators $(\mathrm{Mb})$ and (LDH) and inflammation indicator (IL6) were assessed before and after the plyometric exercise PE session.

- Measuring the pulse rate during plyometric exercise session to determine the severity of performance.

\section{Blood sampling and analysis}

Blood samples were taken from the cubital vein before and after training sessions, while the subjects were in a seated position.

To get the Mb concentration, a ELISA Test Kit (Myoglobin Enzyme Immunoassay Test Kit, Catalog Number: BC-1117) was used. The procedure followed the manufacturer guidelines. Urea was also measured using Urease-Berthelot Method (biodiagnostic,Dokki, Giza, Egypt) according to the manufacturer's instructions.

IL6 was measured using ELISA Kit (Biosourse, KAC1262,Belgium) according to the manufacturer's instructions.

\section{Procedures}

The Subjects performed PE session in a swimming pool with water at a depth of 130 $\mathrm{cm}$ (chest-deep) with a temperature of $28^{\prime \prime} \mathrm{C}$; and the same session on grass land.

This training session included unilateral and bilateral plyometric exercise, the session consists of 15 min warm up, doing one set of exercise to be familiar with PE training and then doing 300 jump as following in the table 2

Table (2) plyometric exercise session

\begin{tabular}{c|c|c|c|c}
\hline Exercise & Sets & Repetition & Rest & Tempo \\
\hline Sumo Squat Jump & 5 & 12 & On $2 \mathrm{~m}$ & Fast \\
\hline Alternating Jump Lunge & 5 & 12 & On $2 \mathrm{~m}$ & Fast \\
\hline
\end{tabular}




\begin{tabular}{c|c|c|c|c}
\hline Streamline Jump & 5 & 12 & On $2 \mathrm{~m}$ & Fast \\
\hline Single Leg Squat Jump (right leg) & 5 & 12 & On 2 $\mathrm{m}$ & Fast \\
\hline Single Leg Squat Jump (left leg) & 5 & 12 & On 2 $\mathrm{m}$ & Fast \\
\hline
\end{tabular}

Interval periods and number of repetitions were determined by reference [22].

\section{Statistics}

Statistical analysis was carried out using SPSS software version 21 (SPSS Inc., Chicago, IL, USA). It was checked that all the variables complied with the assumption of normality (Kolmogorov-Smirnov normality test) so we used parametric statistical.

\section{Results}

There are statistically significance differences between aquatic and grass group in pulse rate by using Independent Samples T test as shown in table (3)

\begin{tabular}{|c|c|c|c|c|c|c|}
\hline \multirow[b]{2}{*}{ Variables } & \multicolumn{2}{|c|}{ Aquatic group } & \multicolumn{2}{|c|}{ Grass group } & \multirow[b]{2}{*}{$\mathrm{T}$} & \multirow{2}{*}{$\begin{array}{l}\text { Sig. } \\
(2- \\
\text { tailed })\end{array}$} \\
\hline & Mean & $\begin{array}{l}\text { Standard } \\
\text { deviation }\end{array}$ & Mean & $\begin{array}{l}\text { Standard } \\
\text { deviation }\end{array}$ & & \\
\hline Pulse rate & 126.8800 & 13.72314 & 157.3067 & 10.17725 & 6.897 & .000 \\
\hline
\end{tabular}

Table (3) aquatic and grass group pulse rate by using Independent Samples T test (t) value on $\mathrm{p} \leq 0.05=2.145$

There are significance increase between Pre- and Post in all biomedical markers (

BUN,Mb,LDH,IL6) of the Aquatic group by using Paired Samples T test as shown in table 4 Table (4) Pre- and Post-biomedical markers of the Aquatic group by using Paired Samples T

\begin{tabular}{c|c|c|c|c|c|c|c|c}
\hline \multirow{2}{*}{} & \multicolumn{2}{|c|}{ Pre } & \multicolumn{2}{c|}{ Post } & Mean \\
\cline { 2 - 8 } & Mean & $\begin{array}{c}\text { Standard } \\
\text { deviation }\end{array}$ & Mean & $\begin{array}{c}\text { Standard } \\
\text { deviation }\end{array}$ & $\begin{array}{c}\text { Standard } \\
\text { difference }\end{array}$ & T & Sig \\
\hline BUN & 23.8667 & 5.87813 & 25.800 & 4.95984 & 1.93333 & 2.91466 & 2.569 & .022 \\
\hline $\mathrm{Mb}$ & 42.6667 & 10.26552 & 53.000 & 12.3866 & 10.33333 & 5.47288 & 7.313 & .000 \\
\hline $\mathrm{LDH}$ & 244.2667 & 47.69466 & 310.40 & 52.9188 & 66.13333 & 45.8115 & 5.591 & .000 \\
\hline IL 6 & 1.8087 & .50468 & 3.9947 & .75560 & 2.18600 & .70326 & 12.04 & .000 \\
\hline
\end{tabular}

test $\mathrm{p} \leq 0.05=2.145$

There are significance increase between Pre- and Post in all biomedical markers (

BUN,Mb,LDH,IL6) of the grass group by using Paired Samples T test as shown in table 5

\begin{tabular}{c|c|c|c|c|c|c|c|c}
\hline \multirow{2}{*}{} & \multicolumn{2}{|c|}{ Pre } & \multicolumn{2}{c|}{ Post } & \multicolumn{2}{c|}{ Mean } & Standard \\
\cline { 2 - 8 } & Mean & $\begin{array}{c}\text { Std. } \\
\text { Deviation }\end{array}$ & Mean & $\begin{array}{c}\text { Std. } \\
\text { Deviation }\end{array}$ & T & Sig \\
\hline BUN & 24.0667 & 4.63630 & 32.0667 & 4.25049 & 8.00000 & 3.22933 & 9.595 & .000 \\
\hline Mb & 41.8667 & 11.36955 & 92.2667 & 19.79707 & 50.40000 & 21.96686 & 8.886 & .000 \\
\hline LDH & 238.3333 & 56.52012 & 311.8667 & 67.15958 & 73.53333 & 41.55696 & 6.853 & .000 \\
\hline IL 6 & 2.0827 & .58099 & 5.8200 & .80009 & 3.73733 & .85758 & 16.88 & .000 \\
\hline
\end{tabular}


Table (5) Pre- and Post-Measurements of the grass group by using Paired Samples T test (t) value on $\mathrm{p} \leq 0.05=2.145$

There are no statistically significance differences between aquatic and grass group Pretraining measurements of all biomedical markers (BUN,Mb,LDH,IL6) by using Independent Samples T test as shown in table 6

\begin{tabular}{c|c|c|c|c|c|c}
\hline \multirow{2}{*}{} & \multicolumn{2}{|c|}{ Aquatic } & \multicolumn{2}{c|}{ Grass } & \multirow{2}{*}{ T } & \multirow{2}{*}{ Sig } \\
\cline { 2 - 5 } & Mean & Standard deviation & Mean & Standard deviation & & \\
\hline BUN & 23.8667 & 5.87813 & 24.0667 & 4.63630 & 0.103 & .918 \\
\hline Mb & 42.6667 & 10.26552 & 41.8667 & 11.36955 & 0.202 & .841 \\
\hline LDH & 244.2667 & 47.69466 & 238.3333 & 56.52012 & 0.311 & .758 \\
\hline IL 6 & 1.8087 & .50468 & 2.0827 & .58099 & 1.379 & .179 \\
\hline
\end{tabular}

Table (6) aquatic and grass group Pre-training measurements of all biomedical markers by using Independent Samples T test $(\mathrm{t})$ value on $\mathrm{p} \leq 0.05=2.145$ there are statistically significant differences between aquatic and Grass group measurements in all variables of the research except $\mathrm{LDH}$ as shown in table 7.

\begin{tabular}{c|c|c|c|c|c|c}
\hline \multirow{2}{*}{} & \multicolumn{2}{|c|}{ Aquatic } & \multicolumn{2}{c|}{ Grass } & \multirow{2}{*}{ T } & \multirow{2}{*}{ Sig } \\
\cline { 2 - 7 } & Mean & $\begin{array}{c}\text { Standard } \\
\text { deviation }\end{array}$ & Mean & $\begin{array}{c}\text { Standard } \\
\text { deviation }\end{array}$ & T & \\
\hline BUN & 25.8000 & 4.95984 & 32.0667 & 4.25049 & 3.716 & .001 \\
\hline $\mathrm{Mb}$ & 53.0000 & 12.38663 & 92.2667 & 19.79707 & 6.512 & .000 \\
\hline $\mathrm{LDH}$ & 310.4000 & 52.91881 & 311.8667 & 67.15958 & 0.066 & .948 \\
\hline $\mathrm{IL} 6$ & 3.9947 & .75560 & 5.8200 & .80009 & 6.424 & .000 \\
\hline
\end{tabular}

Table (7) aquatic and Grass group measurements post training in all of all biomedical markers by using Independent Samples $T$ test $(\mathrm{t})$ value on $\mathrm{p} \leq 0.05=2.145$

\section{Discussion}

The present study aimed to compare serum BUN, Mb, LDH and IL 6 response to aquatic and Grass plyometric session, the results showed that There are significance increase between Pre- and Post in all biomedical markers ( BUN,Mb,LDH,IL6) of the aquatic and grass group as shown in table 4, 5 but the increasing in grass group is significantly higher in all biomedical markers except LDH than aquatic group as shown in table 7.

We can explain the significantly increasing in grass group in BUN, Mb and IL6 as following:

Regarding to the first variable (BUN), evidence suggests that there are factors affect in BUN levels include lean body mass, plasma volume, dietary protein, injury, and type and duration of exercise. Furthermore urea is one of several nitrogen compounds produced when an amino group of an amino acid is removed either for recycling into other proteins or being catabolized for energy or from tissue breakdown.

In this study the duration of exercise was long ( over 1 hour ) and intensity was higher in grass group than aquatic group as showed by Heart rate table, which cause protein catabolic, muscle damage and elevate of BUN.

Regarding to the muscle damage indicators (Mb \&LDH), it is known that strenuous plyometric training can damage the muscle cell membrane, which can result in the leakage of $\mathrm{Mb}$ and $\mathrm{LDH}$, the present findings are in line with the results of previous studies $[10,18,28]$. 
Regarding to the fourth variable (muscle inflammation IL6 )there are a Few of studies talked about the effect of plyometric exercise on inflammation, The results of these studies indicated an immediate significant increase in interleukin 6 (IL-6) immediately after stretchshortening cycle exercise $[9,12]$ This is consistent with the findings of the results of the current study .

However the aquatic group results were more less than grass group in all biomedical markers perhaps because of lower oxidative stress produced by aquatic plyometrics, water buoyancy reduces forces the of impact with land, reduction of body weight in relation to the immersion level and decreasing the risk of injuries such as tendonitis, stress fractures, and other overuse injuries.

The present findings are in line with the results of previous studies, where the aquatic environment has demonstrated less change in muscle damage indicators due to slower and less intensive eccentric contraction and a more rapid neuromuscular recovery $[25,26,28]$. Conclusion

After comparing the experimental groups, it is clear that the aquatic plyometric group had lower statistical differences results than grass plyometric group for indicators of protein catabolism, muscle damage and muscle inflammation, therefore, the water environment provide an optimal environment for athletes to performing plyometric exercise.

\section{Recommendations}

The present study can recommend that coaches and strength \& conditioning professionals use aquatic plyometric or safe surfaces like a firm surface for plyometric training to decrease muscle damage. Moreover, there is no financial support for this project and we did not measure some of the blood indicators of muscle damage, biopsy and MRI, which can be a subject for further research. 


\section{References}

1. Arazi, H.; Asadi, A.( 2011) The effect of aquatic and land plyometric training on strength, sprint, and balance in young basketball players. J. Hum. Sport Exerc. 6, 101-111.

2. Asadi, A.; Saez de Villarreal, E.; Arazi, H. (2015) The effects of plyometric type neuromuscular training on postural control performance of male team basketball players. $\mathrm{J}$. Strength Cond. Res. 29, 1870-1875.

3. Asadi, A.; Arazi, H. (2012) Effects of high-intensity plyometric training on dynamic balance, agility, vertical jump and sprint performance in young male basketball players. J. Sport Health Res. 4, 34-44.

4. Bacharach David W.; Petit, Moira; Rundell, Kenneth W.(1996).Relationship of Blood Urea Nitrogen to Training Intensity of Elite Female Biathlon Skiers. $j$ of Strength and Conditioning Research10(2)105-108.

5. Brancaccio, P., Maffulli, N., and Limongelli, F. (2007). Creatine kinase monitoring in sport medicine. British Medical Bulletin, 81-82(1), 209-230.

6. Brancaccio, P., Limongelli, F., and Maffulli, N. (2006). Monitoring of serum enzymes in sport. British Journal of Sports Medicine, 40, 96-97.

7. Butova, O.A., and Masalov, S.V. (2009). Lactate Dehydrogenase Activity as an Index of Muscle Tissue Metabolism in Highly Trained Athletes. Human Physiology, 35(1), 127-129.

8. Byrne, C.; Eston, R.G. (2002) The effects of exercise-induced muscle damage on isometric and dynamic knee extensor strength and vertical jump performance. J. Sports Sci. 20, 417425.

9. Chatzinikolaou, A., Fatouros, I.G., Gourgoulis, V. (2010). Time course of changes in performance and inflammatory responses after acute plyometric exercise. Journal of Strength and Conditioning. Research, 24(5), 1389-1398

10. Clarkson, P.M., Kearns, A.K., Rouzier, P. (2006). Serum creatine kinase levels and renal function measures in exertional muscle damage. Medicine and Science in Sports and Exercise, 38(4), 623-627

11. Donoghue, O., Shimojo, H., and Takagi, H. (2011). Impact forces of plyometric exercises performed on land and in water. Sports Health, 3(3).

12. Dousset E, Avela J, Ishikawa M. (2007) Bimodal recovery pattern in human skeletal muscle induced by exhaustive stretch-shortening cycle exercise. Medicine \& Science in Sports and Exercise 39(3): 453-460

13. George, D.;Bryan, L. R.; Robert, M.; (2015) current concepts of plyometric exercise . Int J Sports PhysTher. 10(6): 760-786.

14. Haff, G. Gregory, Triplett, N. Travis(2015). Essentials of Strength Training and Conditioning, Fourth Edition,Human Kinetics.

15. Hamid A, Roger E, Abbas A. (2016) Type of Ground Surface during Plyometric Training Affects the Severity of Exercise-Induced Muscle Damage. Sports (Basel). 4(1): 15

16.Impellizzeri,F.M.;Rampinini,E.;Castagna,C. (2008) Effect of plyometric training on sand versus grass on muscle soreness and jumping and sprinting ability in soccer players. Br. J.

Sports Med. 42, 42-46

17. Jakeman, J.R.; Byrne, C.; Eston, R.G. (2010) Lower limb compression garment improves recovery from exercise-induced muscle damage in young, active females. Eur. J. Appl.

Physiol. 109, 1137-1144.

18. Lee, J., Goldfarb, A., Rescino, M. (2002). Eccentric exercise effect on blood oxidativestress markers and delayed onset of muscle soreness. Medicine and Science in Sports and Exercise, 34(3), 443-448.

19. Marginson, V.; Rowland, A.V.; Gleeson, N.P. (2005) Comparison of the symptoms of exercise-induced muscle damage after an initial and repeated bout of plyometric exercise in men and boys. J.Appl. Physiol. 99, 1174-1181. 
20. Marković, G., and Mikulić, P. (2010). Neuro-muskuloskeletal and performance adaptations to lower-extremity plyometric training. Sports Medicine, 40(10), 859-895. 21. Martel, G.F., Harmer, M.L., Logan, J.M. (2005). Aquatic plyometric training increases vertical jump in female volleyball players. Medicine and Science in Sports and Exercise, 37 , 1814-1819.

22. Micheal A. Clark., Scott C. Lucett. (2010) NASM Essentials of sports performance training. Lippincott Wiliams \& Wilkins.

23. Miller, M.G., Berry, D.C., Bullard, S. (2002). Comparisons of land-based and aquaticbased plyometric programs during an 8-week training period. Journal of Sport Rehabilitation, 11(4), 268-283.

24. Miyama, M.; Nosaka, K. (2004) Influence of surface on muscle damage and soreness induced by consecutive drop jumps. J. Strength Cond. Res. 18, 206-211.

25. Pantoja, P.D., Alberton, C.L., Pilla, C. (2009). Effect of resistive exercise on muscle damage in water and on land. j of Strength and Conditioning. Research, 23(3), 1051-1054.

26. Robinson,L.E.;Décor,S.T.;Merrick,M.A. (2004) The effects of land vs. aquatic plyometrics on power, torque, velocity, and muscle soreness in women. J. Strength Cond. Res. 18, 84-91.

27. Serrão, F.V., Foerster, B., Spada, S. (2003). Functional changes of human quadriceps muscle injured by eccentric exercise. Brazilian Journal of Medical and Biological Research, 36(6), 781-786.

28. Shiran, M., Kordi, M., Ziaee, V. (2008). The effect of aquatic and land plyometric training on physical performance and muscular enzymes in male wrestlers. Research Journal of Biological Sciences, 3(5), 457-461.

29. Stemm, J., and Jacobson, B. (2007). Comparison of land- and aquatic- based plyometric training on vertical jump performance. J of Strength and Conditioning. Research, 21(2), 568571.

30. Twist, C.; Eston, R.G. (2009) The effect of exercise-induced muscle damage on perceived exertion and cycling endurance performance. Eur. J. Appl. Physiol. 105, 559-567. 